\title{
PERKAWINAN DALAM KABA BUJANG PIAMAN JO PUTI PAYUANG LAUIK
}

\author{
Vebria Marta Ningsih ${ }^{1 *}$, Silvia Rosa ${ }^{2}$, Muchlis Awwali ${ }^{3}$ \\ vebriamningsih@gmail.com* \\ Fakultas Ilmu Budaya Universitas Andalas ${ }^{1,2,3}$
}

\begin{abstract}
ABSTRAK
Artikel ini mengungkap perjodohan yang terdapat dalam kaba Bujang Piaman Jo Puti Payuang Lauik. Penelitian ini menggunakan analisis sosiologi sastra. Metode yang digunakan adalah metodologi penelitian sosiologi sastra dan teknik yang dilakukan adalah teknik kepustakaan. Penelitian ini menyimpulkan bahwa dalam kaba Bujang Piaman Jo Puti Payuang Lauik versi Selasih terdapat beberapa fakta cerita yaitu pemilihan perjodohan harus dengan orang yang babangso, orang yang jelas asal usulnya dan memiliki karib kerabat di daerah yang ditempatinya, selanjutnya yaitu peran mamak yang telah digantikan oleh seorang ayah dan peranan perempuan yang tidak sesuai lagi dengan perempuan Minangkabau pada umumnya.
\end{abstract}

Kata-kata Kunci : Perkawinan, Kaba, Bujang Piaman Jo Puti Payuang Lauik, Selasih.

\section{MARRIAGE IN KABA BUJANG PIAMAN JO PUTI PAYUANG LAAUIK}

\begin{abstract}
This article reveals the matchmaking contained in the Kaba Bujang Piaman Jo Puti Payuang Lauik. This study uses a sociological analysis of literature. The method used is the sociology of literature research methodology, and the technique used is the literature technique. This research concludes that several facts of the story in the Selasih version of the Kaba Bujang Piaman Jo Puti Payuang Lauik, namely the choice of matchmaking must be with babangso someone who has clear origins and has close relatives in the area where he lives. The role of a mamak whom a father and women's role has replaced is no longer suitable for Minangkabau women in general.
\end{abstract}

Keywords: Marriage, Kaba, Bujang Piaman Jo Puti Payuang Lauik, Selasih.

Jurnal Elektronik WACANA ETNIK - Vol 9 No 2, 2020, (116 - 124) p ISSN 2089-8746, e ISSN 2302-7142

Submit: September 2020. Diterima: September 2020. Publikasi: Oktober 2020. 


\section{PENGANTAR}

Kaba termasuk pada cerita rakyat yang bersifat tradisional yang disampaikan secara turun temurun dari nenek moyang bangsa Minangkabau, Kaba disampaikan secara lisan yaitu disampaikan dari mulut ke mulut. Cerita kaba dihafalkan oleh si tukang cerita (tukang kaba), lalu didendangkan oleh si tukang kaba kepada pendengarnya. Sehingga pada masa itu kaba menjadi sebuah cerita yang utama dan paling diminati oleh masyarakat Minangkabau pada waktu itu. Namun pada akhirnya seiring perkembangan zaman kaba sudah banyak dibukukan dengan menggunakan bahasa Minangkabau klasik ( Junus, 1984:17)

Selain itu menurut Junus (1984:66), kaba merupakan salah satu bentuk cerita rakyat Minangkabau yang mempunyai dua syarat. Pertama, menceritakan suatu peristiwa dan mempunyai audience tertentu, yaitu orang Minangkabau yang hidup dalam dunia tradisi. Kedua, cerita sebenarnya dipolakan kepada cara hidup masyarakat Minangkabau tradisional.

Kaba pada umumnya tergolong ke dalam cerita pelipur lara, yaitu suatu cerita yang pada mulanya menceritakan peristiwa yang menyedihkan, penderitaan, kekecewaan, kesengsaraan, dan perjuangan yang kemudian berakhir kebahagiaan. Sebagaimana disampaikan Navis (1984:243), bahwa kaba pada umumnya berasal dari bahasa Arab akkbar yang dilafalkan ke dalam bahasa Indonesia menjadi kabar dan ke dalam bahasa Minangkabau menjadi kaba. Menurut Junus (1984:18) kaba juga berfungsi untuk mendidik pembacanya bagaimana hidup bermasyarakat dan berbudaya.

Kaba Bujang Piaman Jo Puti Payuang Lauik ini ditulis kembali oleh Sariamin Ismail dengan nama samaran Selasih. Kaba ini diterbitkan oleh Departemen Pendidikan dan Kebudayaan pada tahun 1984. Sariamin Ismail. Lahir di Talu, Talamau, Pasaman Barat, 31 Juli 1909 dan meninggal di Riau, Pekanbaru 15 Desember 1995 pada saat berumur 86 Tahun. Ia adalah pengarang wanita dari angkatan pujangga baru. Kaba Bujang Piaman Jo Puti Payuang Lauik banyak membicarakan kehidupan sosial masyarakat Minangkabau khususnya tentang perkawinan yang terdapat dalam masyarakat Minangkabau. salah satu bentuk perkawinan yang diceritakan adalah persoalan perjodohan Puti Payuang Lauik dan Sutan Lembak Tuah.

Kaba Bujang Piaman Jo Puti Payuang Lauik merupakan salah satu karya sastra yang menarik untuk diteliti dari segi sosiologisnya seperti halnya karya-karya sastra lainnya. Alasan yang melatarbelakangi bahwa kaba ini perlu dianalisis dengan menggunakan kajian sosiologi sastra, ialah bahwa Kaba Bujang Piaman Jo Puti Payuang Lauik ini berlatar sosial karena fenomena-fenomena sosial masyarakatnya seperti perbedaan orang asal dengan orang pedagang (datang). Hal ini juga dapat dilihat pada pemilihan judulnya, yaitu Kaba Bujang Piaman jo Puti Payuang Lauik. Selain itu, latar sosial yang digambarkan sangat jelas.

\section{KERANGKA TEORI DAN METODE}

Menurut Wiyatmi (2005: 97), sosiologi sastra merupakan perkembangan dari mimetik yang memahami karya sastra dalam hubungannya dengan realitas dan aspek sosial kemasyarakatan. tersebut dilatarbelakangi oleh fakta bahwa keberadaan karya sastra tidak dapat terlepas dari realitas sosial yang terjadi dalam masyarakat.

Jurnal Elektronik WACANA ETNIK - Vol 9 No 2, 2020, (116 - 124) p ISSN 2089-8746, e ISSN 2302-7142 
Endaswara (2011:79) memberikan pengertian bahwa sosiologi sastra adalah penelitian yang berfokus pada manusia. Hal ini disebabkan oleh sastra sering mengungkapkan perjuangan manusia dalam menentukan masa depannya, berdasarkan imajinasi, perasaan dan intuisi. Pengarang dan karyanya merupakan dua sisi yang tidak dapat dipisahkan dalam rangka membicarakan sebuah karya sastra. di satu sisi, pengarang adalah anggota dari kelompok masyarakat tersebut. Nilai-nilai sosial pada sebuah cerita dapat diwujudkan untuk mencapai pemahaman yang mendalam.

Soemardjan, (dalam Soekanto, 2017: 17) menyatakan bahwa sosiologi atau ilmu kemasyarakatan merupakan suatu ilmu yang mempelajari tentang struktur sosial dan proses sosial, termasuk perubahan sosial. Struktur sosial merupakan keseluruhan jalinan antara unsur-unsur yang pokok yaitu kaidah-kaidah sosial (norma-norma sosial), lembaga-lembaga sosial, kelompok-kelompok sosial, dan lapisan-lapisan sosial. Proses sosial merupakan pengaruh timbal balik antara kehidupan ekonomi, politik, hukum, agama, dan sebagainya. Salah satu proses sosial yang bersifat tersendiri ialah dalam hal terjadinya perubahan-perubahan di dalam struktur sosial tersebut.

Kaba sebagai suatu karya sastra dibangun berdasarkan dua bagian yaitu, unsur intrinsik dan unsur ekstrinsik. Unsur intrinsik adalah unsur yang berasal dari karya itu sendiri seperti Tokoh dan penokohan dalam sebuah karya, ada istilah tokoh dan penokohan, watak dan perwatakan atau karakter dan karakteristik secara bergantian menunjuk pengertian yang hampir sama (Nurgiyantoro, 1994:164).

Metode penelitian ini dilakukan dengan langkah-langkah sebagai berikut. Peneliti membaca, memahami, mempelajari dengan memahami dan menjelaskan objek yang akan diteliti. Dan mengumpulkan data-data untuk melakukan studi kepustakaan. Pada studi pustaka ini, peneliti akan mencari bahan tertulis atau informasi yang berkaitan dengan objek. Hal ini dimaksud supaya bisa mengembangkan dan memahami data-data yang didapat. Datadata yang telah terkumpul kemudian dianalisis dengan menggunakan teori sosiologi sastra sehingga masalah yang diajukan sebelumnya dapat terpecahkan dan tujuan penelitian ini dapat tercapai. Data- data tersebut berupa peristiwa yang terjadi dan berhubungan dengan objek penelitian. Kemudian menghubungkannya dengan sosiologi sastra dengan cara melihat, mengamati, mendata, dan menganalisisnya.

\section{HASIL DAN PEMBAHASAN}

Secara naluri manusia merupakan makhluk sosial yang tidak mampu hidup sendiri. Karena manusia tidak akan mampu bertahan hidup tanpa bantuan orang lain, sekalipun ia hidup dengan bergelimang kemewahan dan serba berkecukupan. Dalam konteks ini berarti bahwa kehadiran orang lain merupakan suatu kebutuhan primer. Dalam hidup ini kehadiran orang lain tersebut dapat berupa teman biasa atau teman akrab. Kedua bentuk hubungan ini dapat berupa suatu hubungan yang lebih intim, yakni suatu ikatan perkawinan (Awwali, 2015: 7).

Kaba Bujang Piaman Jo Puti Payuang Lauik menggambarkan salah satu bentuk perkawinan yang ada di masyarakat Minangkabau, khususnya di Pasaman. Bentuk perkawinan yang dijelaskan dalam kaba tersebut ialah perkawinan ideal. Perkawinan ideal ialah perkawinan pulang ka bako atau pulang ka mamak. Maksud dengan perkawinan pulang ka bako ialah seorang anak menikah dengan anak saudara laki-laki ibunya. Artinya, perkawinan

Jurnal Elektronik WACANA ETNIK - Vol 9 No 2, 2020, (116 - 124) p ISSN 2089-8746, e ISSN 2302-7142 
terjadi disebabkan orang tua kedua pasangan mempelai bersaudara (laki-laki dan perempuan bersaudara). Menurut adat, perkawinan ini diibaratkan sarupo kuah tabuang ka nasi atau jangguik tumbuah di daguak (serupa kuah terbuang ke nasi atau jenggot tumbuh di dagu). Tujuan dari perkawinan ini adalah untuk memperkuat hubungan silaturrahmi antarsesama keluarga dan menjaga keutuhan harta pusaka kaum (Awwali,2015:9).

Kaba tersebut menceritakan tentang persoalan perjodohan salah seorang anak raja yang bernama Puti Payuang Lauik. Sang raja hendak menjodohkan anaknya dengan Sutan Lembak Tuah yang merupakan kemenakannya sendiri. Alasannya ialah karena Sutan Lembak Tuah juga berasal dari keturunan raja yang nantinya bisa melanjutkan kedudukannya sebagai raja. Bentuk perkawinan yang diinginkan oleh Raja Parik Batu adalah pulang ke mamak, yaitu ia ingin Sutan Lembak Tuah pulang ke anak mamak atau disebut dengan perkawinan ideal.

Akan tetapi perjodohan tersebut ditolak oleh Puti Payuang Lauik, karena ia lebih memilih kekasihnya yang bernama Bujang Piaman. Puti Payuang Lauik dan Bujang Piaman saling jatuh cinta pada saat pertemuan pertama mereka ketika puti Payuang Lauik pergi berkuda dengan kakaknya, Sutan Sari Alam. Hingga akhirnya hubungan mereka tersebut berjalan dengan sebaik mungkin. Tapi tidak dengan adat yang ada pada masyarakat di Pasaman. Di mana adat melarang menikah dengan orang yang bukan keturunan raja atau orang pendatang. Walaupun orang tersebut adalah seorang pedagang yang sukses. Namun tetap tidak berterima dengan penduduk asa. Karena orang pendatang dianggap tidak memiliki karib kerabat dan tidak jelas asal-usulnya.

Akan tetapi, perjodohan tersebut tetap ditolak oleh Puti Payuang Lauik. Karena Puti Payung Lauik telah memilih jodohnya sendiri yaitu Bujang Piaman, lelaki yang dicintainya. Mereka berdua memutuskan untuk menikah secara diam-diam tanpa restu dari kedua orang tua Puti Payuang Lauik. Terdapat pada kutipan berikut ini.

"larangan adaik jo ugamo,sarato doso nan ka tibo,kini cubo sabuikkan, amuah koh adiak dinikahkan, indak satau ayah kito, sarato ibu kanduang kito. ”(Selasih, 1983:80)

"larangan adat dengan agama, serta dosa yang akan datang, sekarang coba sebutkan, maukah adik dinikahkan, tidak tahu ayah kita, serta ibu kandung kita."(

"disuntiang rambuiknyo yo saketek, si Bujang alah bapakai pulo, lah duduak urang kasadonyo, di bawah tirai langik-langik, dilangsuangkan malah akaik nikah, bakato sakada nan paralu, haniang tanang di tangah rumah."(Selasih, 1983:88)

"tidak kita panjangkan kisah, dengan kedatangan Upiak Reno Manih, disuruhnya pakai kebaya, disunting rambutnya yang sedikit, Si Bujang sudah berpakaian, telah dudk orang semuanya, di bawah tirai langit-langit, dilangsungkan akad nikah, berkata sekedarnya saja, diam tenang di tengah rumah."

Dari kutipan di atas, penulis menceritakan tentang bentuk perkawinan yang dilakukan oleh Puti Payuang Lauik dengan Bujang Piaman. Akan tetapi perkawinan tersebut tidak diketahui oleh ayah dan ibunya Puti Payuang Lauik. Perkawinan ini dapat dikatakan sebagai perkawinan terlarang. Di mana perkawinan terlarang tersebut dapat merusak struktur adat suku bangsa Minangkabau karena dapat merusak struktur keturunan.

Perihal menentukan jodoh yang pantas untuk anak perempuan, dalam Kaba Bujang Piaman Jo Puti Payuang Lauik digambarkan melalui seorang ayah lebih memilih kemenakannya sendiri untuk menjadi calon menantunya 
karena Raja Parik Batu merasa telah mengenal kemenakannya dan merasa bahwa kemenakannya tersebut cocok untuk anaknya. Selain sebagai kemenakan dari Raja Parik Batu, Sutan Lembak Tuah juga termasuk orang yang kaya dan terpandang di kampung tersebut. Hal inilah yang menjadi alasan bagi Raja Parik Batu untuk menjodohkan anaknya dengan Sutan Lembak Tuah. Bahkan Raja Parik Batu tidak akan memilih orang lain sebagai menantunya walaupun telah diadakan gelanggang dalam hal pemilihan perjodohan untuk putrinya. Terdapat dalam kutipan berikut ini.

"sabagai itu pulo mamak, pado pikiran ambo, usah galanggang lamo-lamo, iyo sampai babulanbulan, cukuik sapakan duo pakan, usah kito talampau payah, jangan pulo barabiah bana, nan di hati denai iko, indak mancari urang lain, sabab dek inyo kamanakan, iyolah Sutan Lembak Tuah, lah mah patuik itu ngaran, iyo pulang ka anak ambo. "(Selasih, 1983:99)

"sebagai itu mamak, pada pikiran saya, tidak usah gelanggang lama-lama, iya sampai berbulanbulan, cukup seminggu dua minggu, tidak usah kita terlampau susah, jangan terlalu berlebihan, yang dihati saya, tidak akan mencari orang lain, sebab ia adalah kemenakan saya, ialah Sutan Lembak Tuah, sudah seharusnya, ia pulang ke anak saya."

Dari kutipan di atas, penulis menjelaskan bahwa walaupun telah diadakan sayembara untuk memilih jodoh Puti Payuang Lauik. Sebagai seorang mamak dan seorang ayah, Raja Parik Batu ingin melepaskan tanggung jawabnya sebagai mamak. Ia tetap akan memilih Sutan Lembak Tuah sebagai jodoh anaknya, yang disebut dengan pulang ke anak mamak.

Setelah acara gelanggang selesai, Puti Payuang Lauik diminta untuk menentukan pilihannya. Pada akhirnya Puti lebih memilih Bujang Piaman sebagai jodohnya. Akan tetapi raja Parik Batu terkejut dengan keputusan putrinya. Sehingga membuatnya semakin marah. Hal ini terdapat pada kutipan berikut ini.

"bakato sanan Payuang Lauik, bakato tapatah-tapatah, ayam kuriak rambaian jalak, sadang mangaih dalam padi, ambiak tampuruang bari makan, alah ditiliak dari nan banyak, Bujang Piaman tampek hati, nan lain buliah diharamkan, tatakua urang nan banyak, tapi ndak ado nan mangecek, takuik kecekt salah sasek, padang jo ameh taruahannyo, nan labiah takajuik itu ngaran, iyo tuanku Parik Batu, sarato tuanku Andeh Suri, indaknyo sangko saketek juo, anaknyo nan salalu patuah, nan manuruik sagalo kato, kan bapikia nan bak kian. ”(Selasih, 1983:118)

"berkata Payung Lauik, berkata terpatah-patah, ayam kurik rambaian jalak, sedang mengais dalam padi, ambil tempurung beri makan, sudah di lihat dari yang banyak, Bujang Piaman tempat dihati, yang lain boleh diharamkan, termenung orang banyak, tapi tidak ada yang berbicara, takut berbicara salah, padang dengan emas taruhannya, yang lebih terkejut, ia tuanku Parik Batu, serta Tuanku Andeh Suri, tidak disangka sedikitpun, anaknya yang selalu patuh, yang menurut segala perkataan, yang berpikir seperti itu."

Dari kutipan kaba di atas, penulis menjelaskan bahwa seorang anak perempuan memutuskan pilihannya kepada seorang anak pedagang yang bernama Bujang Piaman. Dalam hal ini keluarga pun tidak menyangka kalau anak perempuan satu-satunya yang penurut dan patuh akan menentang keputusan orang tuanya dan mengutamakan pilihannya sendiri.

Dari keputusan tersebut, keinginan Puti Payuang Lauik tidak disetujui oleh raja Parik Batu dan ibunya karena perbedaan status sosial yang mereka miliki. Bujang Piaman merupakan rakyat biasa yang bukan keturunan dari raja. Bahkan Bujang Piaman hanyalah seorang pendatang yang tidak jelas asal-usulnya. Tentunya alasan tersebut menjadi

Jurnal Elektronik WACANA ETNIK - Vol 9 No 2, 2020, (116 - 124) p ISSN 2089-8746, e ISSN 2302-7142 
alasan yang kuat bagi orang tua Payuang Lauik untuk menolak Bujang Piaman. Selain itu, Puti Payuang Lauik sejak kecil sudah ditunangkan dengan Sutan Lembak tuah. Hal ini terdapat pada kutipan berikut ini.

"ndak mungkin pulo itu dangai, inyo indak tau kan larangan, larangan kawin jo rang biaso, nan bukan rajo atau sutan, lah acok juo dikilekkan, inyo batunangan sajak ketek, jo kakaknyo Sutan Lembak Tuah, urang nan akan jadi rajo, manggantikan ayah kanduangnyo. "(Selasih, 1983:118)

"tidak mungkin itu, ia tidak tahu larangan, larangan menikah dengan orang biasa, yang bukan raja atau sutan, sudah sering dikatakan, ia bertunangan dari kecil, dengan kakaknya Sutan Lembak Tuah, orang yang akan jadi raja, menggantikan ayah kandungnya."

Dari kutipan di atas, dapat disimpulkan bahwa antara Puti Payuang Lauik dan Bujang Piaman mempunyai perbedaan status sosial karena Bujang Piaman hanyalah rakyat biasa yang bukan keturunan dari raja ataupun sultan. Keluarga tersebut dianggap tidaklah sederajat dengan keluarga raja. Perjodohan pun sangat ditentang dengan orang pendatang atau urang dagang karena perkawinan harus dilakukan dengan orang yang jelas asal usulnya dan status calon menantu sangat penting bagi urang asa.

Status sosial merupakan kedudukan seseorang secara umum dalam kelompok sosialnya. Status pada dasarnya digolongkan menjadi tiga hal, yaitu ascribe status, achieved status dan assigned status. Ascribe status adalah kedudukan seseorang dalam masyarakat tanpa memperhatikan perbedaan rohaniah dan kemampuan. Kedudukan tersebut diperoleh karena kelahiran, misalnya anak seorang bangsawan maka sampai besar ia dianggap bangsawan pula. Achieved status adalah kedudukan yang diperoleh seseorang dengan cara diperjuangkan dan usaha-usaha yang disengaja oleh individu itu sendiri. Misalnya untuk menjadi seseorang anggota legislatif maka ia harus memenuhi syarat tertentu. Jika terpilih nantinya maka kedudukannya dalam masyarakat akan berubah. Assigned status yaitu kedudukan yang diperoleh seseorang karena pemberian sebagai penghargaan jasa dari kelompok tertentu. Biasanya orang yang telah diberikan status tersebut memiliki jasa karena memperjuangkan sesuatu untuk memenuhi kebutuhan dan kepentingan masyarakat (Asri, 2014:25:26)

Perjodohan yang dilakukan oleh orang tua sering kali menimbulkan konflik yang sangat fatal. Jika salah satu dari mereka telah mempunyai jodohnya sendiri, seperti yang terjadi dalam Kaba Bujang Piaman Jo Puti payuang Lauik, Puti Payuang Lauik telah memilih Bujang Piaman sebagai pilihan hatinya. Dengan begitu ia menentang perjodohannya dengan Sutan Lembak tuah karena ia telah mengambil keputusan untuk tetap memilih Bujang Piaman sebagai jodohnya. untuk menghindari perjodohan tersebut kakak Puti Payuang lauik yaitu Sutan Sari Alam mengatur beberapa siasat agar perjodohan tersebut batal. Terdapat pada kutipan berikut ini:

"bakato kini Sutan Sari Alam, dari tadi inyo aniang sajo, duduak tamanuang tunduak tangadah, manolah adiak Bujang Piaman, ambo mandapek aka lain, untuang adiak laei panjang umua, kito nantik sapakan nangko, sampai adiak cegak bana, koklah cegak Bujang baeko, kok lah kuat naiak kudo, bakudo adiak jo kak Malin, kito katokan pulang kakampuang, mancari ubek ka Piaman, duo hari sasudah itu kito kabakan ka rang banyak, adiak yo ndak sampai pulang, alah mah mati tangah jalan, bia kak Sari nan maratok, indakkan baapo itu ngaran, sahari duo sudah itu, mandanga adiak nan lah mati, si Payuang pulo mambunuah diri iyo pado patang hari, ambo sadiokan malah darah, dari ayam kok darah kambiang, ditebak sapanjang jalan, dari tampek babuainyo, langsuang ka tangah rumah gadang, anyo kami bujua beko, jo kaian jarang di mukonyo, amak dicaliak urang banyak, malam inyo dimandikan, iyo dek andeh sarato dayang, di kapani dek Katik Basa, ambo lai

Jurnal Elektronik WACANA ETNIK - Vol 9 No 2, 2020, (116 - 124) p ISSN 2089-8746, e ISSN 2302-7142 
nan ka manolong, tapi nan ka dikapani, iyolah batang pisang ajo, si payuangg lari jo dubalang, dubalang nan alah tau juo, iyo rasio kito nangko."(Selsih, 1983:157-158)

"berkata kini Sutan Sari Alam, dari tadi dia diam saja, duduk termenung tunduk tengadah, manalah adik Bujang Piaman, saya mendapat akal, untung adik lae panjang umur, kita nanti sapakan kini, sampai adik sehat, kalau lah sehat Bujang Piaman nanti, kalau lah kuat naik kuda, berkuda adik dengan Malin, kita katakan pulang kekampung, mencari obat ke Pariaman, dua hari sesudah itu kita kabakan ke orang banyak, adik tidak sampai pulang, telah meninggal di tengah jalan, biar kak Sari yang menangis, tidak apa- apa itu, dua hari sesudah itu, mendengarkan adik nan lah meninggal, si Payuang dia membunuh diri pada petang hari, saya sediakan darah, dari darah ayam atau darah kambing, ditebak sepanjang jalan, dari tempat buayan, langsung ke tengah rumah gadang,dia kami bujua nanti, dengan kain jarang di mungkanya, Amak lihat orang banyak, malam dia di mandikan, oleh Andeh serta dayang, dikafani dek Katik Basa, saya akan menolong, tapi yang dikafani, ialah batang pisang, si Payung lari dengan Dubalang, Dubalang telah tahu juga, ia rahasia kita ini."

Kutipan di atas menjelaskan bahwa besarnya cinta yang mereka miliki, membuat seorang kakak ikut berjuang mempertahankan cinta mereka. Dengan siasat yang diberikan oleh sang kakak terhadap saudara perempuannya agar cinta mereka tetap berjalan dengan baik seperti yang mereka impikan. Perjuangan tersebut mereka lakukan agar nantinya Puti Payuang Lauik dengan Bujang Piaman dapat bersatu seperti yang mereka impikan.

Sebesar apa pun perjuangan yang mereka lakukan, akan tetapi sikap yang dimiliki oleh orang tua Puti Payuang Lauik tetap tidak menyetujuinya yang memilih Bujang Piaman sebagai jodohnya sendiri. Perselisihan pendapat tersebut mengakibatkan kekacauan terhadap proses pernikahan yang akan mereka laksanakan. Pada akhirnya pernikahan pun tertunda. Hingga akhirnya Puti Payuang Lauik pun memilih bunuh diri. Orang tua Puti tidak menyangka kalau Puti akan melakukan tindakan bunuh diri dengan darah berserakkan di atas ruang tengah. Terdapat dalam kutipan berikut ini.

"limo hari sasudah itu, tandanga tabuah larangan, babunyi iyo panjang bana, duo tujuah galuguik, diguguah kareh-kareah bana, disalo pulo yo dek aguang, babunyi sampai tujuah kali, bahamburan urang banyak, talabiah manti jo panghulu, balari anjiang ka ustano, jaleh tabuah tu tando buruak, siapo ngaran nan lah mati, lah tibo urang di halaman, tampak darah baserak-serak darah iduik alum lae baku, sampai ka anjungan badarah juo, alum sampai urang mambasuah, di ateh lamin ruang tangah, tampak kini mayik tabujua, iyo di ateh tilam bungo, itan di ateh palaminan, lamin galanggang alun dibuka, karano urang kabaralek. "(Selasih, 1983:165)

"lima hari seseudah itu, terdengar tabuh larangan, berbunyi panjang sekali, dua kali tujuh galuguk, diguguh orang keras-keras, disela dengan agung, berbunyi sampai tujuh kali, berhamburan orang banyak, terlebih manti dengan penghulu, berlari anjing ke istana, jelas tabuh itu tanda buruk, siapa yang telah mati, telah tiba orang di halaman, terlihat darah berserakan darah hidup yang belum beku, sampai ke anjungan berdarah juga, belum sampai orang membasuh, di atas lamin ruang tengah, terlihat mayat terbujur, ia di atas tilam bunga, yang di atas pelaminan, lamin gelanggang yang belum dibuka, karena orang akan mengadakan helat perkawinan."

Dari kutipan di atas menjelaskan tentang siasat yang telah diancang oleh Sutan Sari Alam untuk Bujang Piaman dan Puti Payuang Lauik yaitu pulang ke kampung halaman Bujang Piaman yaitu di Pariaman. Di kampung halaman Bujang Piaman tersebut, diadakanlah helat perkawinan berhari-hari dan menjalang ninik mamak. Terdapat pada kutipan berikut ini:

Jurnal Elektronik WACANA ETNIK - Vol 9 No 2, 2020, (116 - 124) p ISSN 2089-8746, e ISSN 2302-7142 
"lah sudah malah baralek, baralek bahari-hari, saroman urang nikah kawin, baarak arak hilia mudiak, manjalang niniak mamak, iyo kaduo belah pihak, Malin Duano dan Bidadasari, induak bako kaduonyo, bapak ketek bapak gadang, abih dijalang kasadonya, iyo dek Buyuang jo padusinyo, nan baru pulang dari Pasaman. "(Selasih, 1983:186-187)

“ setelah perhelatan berhari-hari, seperti orang nikah kawin, berarakan hilir mudik, menjalang ninik mamak, ia kedua belah pihak, Malin Duano dan Bidadasari serta bakonya, bapak kecil bapak besar, dijalang semuanya, ia di Buyung dengan perempuannyo, yang baru pulang dari Pasaman."

Dari paparan di atas dapat disimpulkan bahwa setelah melakukan alek selama berhari-hari Puti Payuang Lauik dan Bujang Piaman melakukan suatu tradisi yang ada di Minangkabau seperti melakukan manjalang induak bako, ninik mamak, bapak besar dan bapak kecil.

Jadi, yang lebih berhak menentukan perjodohan pada zaman dahulu adalah sang ayah bukan mamak sebagai keluarga matrilineal dari anak perempuan tersebut. Dari perjodohan tersebut anak perempuan yang dicerminkan sebagai bundo kanduang dalam suatu adat Minangkabau tidak terlihat sebagai anak yang penurut terhadap orangtuanya akan perihal perjodohan. Dapat dilihat dalam kaba Bujang Piaman Jo Puti Payuang Lauik, bahwa anak perempuan tetap bersikukuh tidak ingin dijodohkan dengan kemenakan ayahnya yang bernama Sutan Lembak Tuah yang merupakan keturunan dari raja atau sutan. Perempuan sebagai bundo kanduang dalam masyarakat Minangkabau mencerminkan sikap yang penurut dan taat terhadap adat budaya yang ada. Bukan malah sebaliknya dalam kaba ini yaitu ingin adanya pembaharuan adat yang memisahkan antara keluarga raja dengan rakyat biasa. Masyarakat Minangkabau dalam Kaba Bujang Piaman Jo Puti Payuang Lauik mencerminkan stratifikasi sosial sebagai sebuah konsep dalam masyarakatnya yang lebih memandang asal usul keturuan bangsawan (urang babangso) lebih tinggi derajatnya dari pada rakyat biasa.

Menurut Kato (2005: 51-52) sistem stratifikasi dalam nagari Minangkabau tradisional memperlihatkan adanya dua karakteristik. Pertama stratifikasi berdasarkan ciri keturunan dan bukan profesi. Kedua, jika urang asa berpindah ke tempat lain dari nagari asal, mereka harus mencari suku yang mau menerima mereka sebagai urang datang di nagari yang baru.

\section{PENUTUP}

Tidak semua fakta mencerminkan realitas sosial masyarakat Minangkabau. namun kaba ini dapat memberikan nilai-nilai dan pengajaran terhadap generasi muda tentang adat dan budaya yang ada pada saat sekarang ini. Selanjutnya dapat menjadi pedoman hidup mengenai akhlak yang baik dalam kehidupan masyarakat Minangkabau. Setelah melakukan penelitian terhadap Kaba Bujang Piaman Jo Puti Payuang Lauik, terdapat nilainilai yang tidak sesuai dengan fakta yang ada dalam realitas sosial masyarakat Minangkabau, yaitunya dalam hal masalah perjodohan berserta orang yang berperan di dalamnya. Di dalam kaba tersebut proses perjodohan digambarkan sangat sederhana, dan orang yang berperan di dalamnya berbeda dengan yang ditemui di tengah-tengah masyarakat. 
Dari paparan di atas, dapat disimpulkan bahwa penulis menjelaskan tentang perubahan yang terjadi dalam $k a b a$ adalah acara meminang yang tidak dilakukan sebelum acara prosesi perkawinan mereka langsung ke perhelatan perkawinan. Berdasarkan realitas sosial Minangkabau dalam prosesi perkawinan salah satu yang harus dilakukan adalah meminang atau batimbang tando. Jika meminang telah dilakukan barulah dapat dikatakan prosesi perkawinan tersebut sesuai dengan adat budaya Minangkabau. Karena adat budaya yang telah ada takkan lekang oleh waktu.

\section{REFERENSI}

Amir . M.S. 1997. Adat Minangkabau Pola dan Tujuan Hidup Orang Minangkabau. Jakarta : PT Mutiara Sumber Widya

Andriani, Nini dkk . 2012. "Citra Perempuan dalam Kaba Bujang Piaman Jo Puti PayuanG Lauik Versi Selasih.” Jurnal Pendidikan Bahasa dan Sastra Indonesia, Volume1 No.1. Diakses pada Tanggal 29 Oktober 2018.

Asri, Yasnur. 2014. Formasi ideology Budaya dalam Novel Pengarang Etnis Pangangan. UNP Press

Awwali, Muchlis. 2015. Pelangi di Minangkabau. Padang: SURI Surau Institute for Conservation Endraswara, Suwardi. 2011. Metodologi Penelitian Sastra. Yogyakarta: Caps.

Hidayat, Hari. 2011.'Perjodohan dalam Naskah Randai ‘Puti Manih Talonsong’ KaryaWisran Hadi Tinjauan Sosiologi Sastra”. Skripsi. Padang: Fakultas Ilmu Budaya Universitas Andalas.

Junus, Umar. 1984. Kaba dan Sistem Sosial Minangkabau, Suatu Problema, Sosiologi Sastra. Jakarta: Balai Pustaka. Kato, Tsuyoshi. 2005. Adat Minangkabau dan Merantau dalam Prespektif Sejarah. Jakarta. Balai Pustaka

Miltos, Andi. 2011.'Realitas Sosial Masyarakat Minangkabau dalam Kaba Magek Manandin”. Skripsi. Padang: Fakultas Ilmu Budaya Universitas Andalas

Navis, A.A. 1984. Alam Takambang Jadi Guru Adat dan Kebudayaan. Jakarta: Grifiti Pers

Ningsih, Dewi Septia. 2013." Konflik Perkawinan dalam Novel Rinai Kabut Singgalang Karya Muhammad Subhan Tinjauan Sosiologi Sastra.” Skripsi. Padang: Fakultas IlmuBudaya Universitas Andalas.

Nurgiyantoro, Burhan.1994. Teori Pengkajian Fiksi. Yogyakarta:Gadjah Mada Universitas Press

Selasih, 1983. Kaba Bujang Piaman Jo Puti Payuang Lauik. Jakarta: Buku Sastra Indonesia dan Daerah

Semi, M. Atar. 1988. Anatomi Sastra. Padang: Angkasa Raya

Stanton, Robert. 1964. Teori Fiksi. Yogyakarta: Pustaka Pelajar Offset

Suria Sumantri, Jujun. 1996. Filsafat Ilmu Sebuah Pengantar Populer.Jakarta: Pustaka Sinar Harapan

Soerjono, Soekanto. 2017. Sosiologi Suatu Pengantar. Jakarta: PT Raja Grafindo Persada

Sudjiman, Panuti. 1992. Memahami Cerita Rekaan. Jakarta: Pustaka Jaya

Tuloli, Nani. 2000. Kajian Sastra. Gorontalo. BMT Nurul Jannah

Wellek dan Werren.1990. Teori Kesusastraan. Jakarta: Gramedia

Wiyatmi. 2005. Pengantar Kajian Sastra. Yogyakarta: Pustaka Book Publisher 